\title{
Improving Anti-CD45 Antibody Radioimmunotherapy Using a Physiologically Based Pharmacokinetic Model
}

\author{
Peter Kletting ${ }^{1}$, Donald Bunjes ${ }^{2}$, Sven N. Reske ${ }^{1}$, and Gerhard Glatting ${ }^{1}$ \\ ${ }^{1}$ Klinik für Nuklearmedizin, Universität Ulm, Ulm, Germany; and ${ }^{2}$ Innere Medizin III, Universität Ulm, Ulm, Germany
}

\begin{abstract}
Radioimmunotherapy is a method to selectively deliver radioactivity to cancer cells via specific antibodies. A strategy to enhance the efficacy of radioimmunotherapy is the prior application of unlabeled antibody, resulting in an increase in the dose to the target tissue and a decrease in the burden to other organs. It was suggested that optimizing this approach might considerably improve radioimmunotherapy with anti-
\end{abstract} CD45 antibody. The present work develops a physiologically based pharmacokinetic model to individually determine the optimal preload for radioimmunotherapy with the YAML568 antiCD45 antibody for each patient. Methods: A physiologically based pharmacokinetic model was developed to describe the biodistribution of anti-CD45 antibody. The transport of antibody to the organs of interest via blood flow, competitive binding of unlabeled and labeled antibody, degradation and excretion of antibody, and physical decay were included in the model. The model was fitted to the biokinetics data of 5 patients with acute myeloid leukemia. On the basis of the estimated parameters, simulations for a 0- to 534-nmol preload of unlabeled antibody were conducted and the organ residence times were calculated. Results: The measured data could be adequately described by the constructed model. The estimated numbers of accessible antigens in the respective organ, in nanomoles, were $97 \pm 33$ for red marrow, $49 \pm 24$ for liver, $34 \pm 18$ for spleen, $38 \pm 31$ for lymph nodes, and $0.9 \pm 0.4$ for blood. These ranges indicate high interpatient variability. The optimal amount of unlabeled antibody identified by simulations would improve the ratio of residence time in red marrow to residence time in liver by a factor of 1.62.4. Conclusion: The efficacy of radioimmunotherapy using anti-CD45 antibody can be considerably increased with the presented model. A more selective delivery of radioactivity to the target organ and a reduction in the toxicity to normal tissue are achieved by determining the optimal preload. Furthermore, the adverse effects of radioimmunotherapy might be drastically reduced while saving antibody expenses. The validation of the model is ongoing. The model is easily extendible and therefore most probably applicable to radioimmunotherapy of other hematologic malignancies, such as antibodies targeted to CD20, CD33, or CD66.

Received May 8, 2008; revision accepted Oct. 23, 2008.

For correspondence or reprints contact: Gerhard Glatting, Klinik für Nuklearmedizin, Universität UIm, D-89070, Ulm, Germany. E-mail: gerhard.glatting@uni-ulm.de

COPYRIGHT ( 2009 by the Society of Nuclear Medicine, Inc.
Key Words: radioimmunotherapy; PBPK model; anti-CD45 antibody; preload

J Nucl Med 2009; 50:296-302

DOI: 10.2967/jnumed.108.054189

$\mathbf{I}_{\mathrm{n}}$ n radioimmunotherapy, a specific antigen is targeted to selectively deliver radioactivity to cancer cells. Radioimmunotherapy of blood-borne cancers has been the most successful because of high accessibility of the target antigen expressed on inherently radiosensitive cells (1). For treatment of acute myeloid leukemia, monoclonal antibodies have been directed to CD33 (2,3), CD66 (4-6), and CD45 (7-9), and studies using anti-CD45 have shown the most promising results (10).

In general, various methods or concepts are applied to improve the biodistribution of radiolabeled monoclonal antibodies (11). Pretargeting and dose fractionation have proved to be efficient in increasing the delivery of radiation to the target tumor $(1,12)$. Another strategy to achieve a more favorable biodistribution for radioimmunotherapy is the application of unlabeled antibodies, that is, preloading $(9,13-16)$. For radioimmunotherapy with anti-CD45 antibody, in some studies different amounts of unlabeled antibodies have been injected before the application of labeled antibody $(9,15,16)$. These studies showed the positive effect of unlabeled antibodies on biodistribution and high interpatient variability. Therefore, the optimal amount of unlabeled antibody seems to depend on the individual patient $(9,12)$. However, selective delivery has not been optimized, and an individualized approach is needed to avoid supersaturation or insufficient saturation, as both could strongly decrease the efficacy of the therapy.

An individualized method to quantify the optimal amount of administered unlabeled antibody must include all relevant information about the patient and must account for biologic variability. The use of an empiric nonparametric modeling approach (17) is not appropriate for this purpose, since it is not possible to model the saturation effect, which is based on different blood flows and numbers of antigens in the organs. For modeling the biokinetic 
behavior of antibodies, physiologically based pharmacokinetic (PBPK) models have the advantage of being able to determine parameters with physiologic meaning $(18,19)$. If parameters represent a physiologic quantity, the described process is better understood and other inputs (such as the varying amounts of unlabeled antibody) can be simulated. PBPK models have been developed previously to describe the biokinetics of antibodies that are directed to solid tumors (20-22). However, to our knowledge, no model for hematologic malignancies in this form and no model with competitive binding of labeled and unlabeled antibody have been presented and evaluated for clinical relevance.

Here, a PBPK model is developed for the anti-CD45 antibody YAML568, a non-2FcR-binding rat IgG2a (9). On the basis of estimated model parameters, various preloading conditions - that is, different amounts of unlabeled antibody - were investigated to find the most favorable biodistribution. The potential improvement applying this individualized approach is estimated.

\section{MATERIALS AND METHODS}

\section{Experimental Protocol}

Patient characteristics $(n=5)$ are presented in Table 1. All patients signed an informed consent form for this study, which was approved by the local ethics committee and the national radiation protection authorities.

The measurements were performed as described elsewhere (9). In brief, the patients received an intravenous injection of 30-47 $\mathrm{mg}(0.5 \mathrm{mg} / \mathrm{kg})$ of unlabeled antibody $16-34 \mathrm{~min}$ before the intravenous injection of $121 \pm 21 \mathrm{MBq}$ of ${ }^{111}$ In-labeled antiCD45 antibodies as a slow intravenous push. Blood samples were obtained at 5, 10, and $30 \mathrm{~min}$; at 1 and $2 \mathrm{~h}$; and at $1 \mathrm{~d}, 2 \mathrm{~d}, 3$ or $5 \mathrm{~d}$, and $6 \mathrm{~d}$ after injection. The ${ }^{111}$ In activity was measured using a $\gamma$-counter (Auto- $\gamma$-5003; Canberra Packard). Planar whole-body scintigraphy (anterior and posterior) with a double-head $\gamma$-camera (ECAM; Siemens) was performed at 2 and $4 \mathrm{~h}$ and at $1 \mathrm{~d}, 2 \mathrm{~d}, 3$ or $5 \mathrm{~d}$, and $6 \mathrm{~d}$ after injection to evaluate the distribution and elimination of the radiotracer. Percentage administered doses were calculated using the ULMDOS program (23).

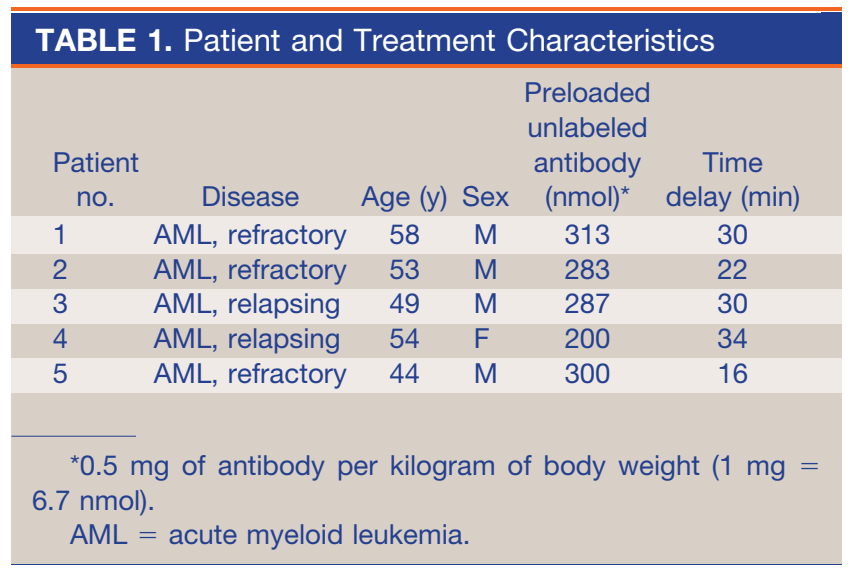

\section{Model Development}

A PBPK model was constructed to describe the biodistribution of labeled and unlabeled anti-CD45 antibodies using SAAM2 (University of Washington) (24). Based on the studies of Matthews et al. $(25,26)$, the model includes blood, liver, spleen, red marrow, and the lymph nodes as sites of antigens (Figs. 1 and 2), since the CD45 antigen is expressed by most hematopoietic cells, lymphoblasts, myeloblasts, and myeloid leukemic cells but not by nonhematopoietic cells $(9,10)$. Specific antibody uptake was incorporated from the plasma compartment of each organ to the antigen compartment directly (27), since in liver, spleen, red marrow, and lymph nodes blood flows through discontinuous capillaries (openings are up to 300 -fold greater than the diameter of the antibody) $(28,29)$. The accessibility of cancer cells is also high, since in more than $90 \%-95 \%$ of all cases acute myeloid leukemia is a diffuse disease with no focal or solid lesions. Thus, prompt uptake of antibody to cancer cells and to bystander cells expressing CD45 can be assumed (27). This is in contrast to PBPK models including solid tumors, where the transport of the antibody through the capillary wall to the interstitial spaces has to be explicitly considered, such as in the 2-pore model of Rippe and Haraldson (20-22).

For the blood flow, $\mathrm{F}_{\mathrm{i}}$, to the organs and the corresponding vascular volumes, the values of the blood circulation model for reference man were used (30). However, only vascular spaces, $\mathrm{V}_{\mathrm{i}}$, of the organs of interest and of the gastrointestinal tract are explicitly implemented; other vascular spaces (e.g., veins, arteries, and heart) are merged into a single compartment. To ensure parsimony, the distribution of antibody to the interstitial spaces was not explicitly incorporated into the model because ready access (due to sinusoid capillaries) of antibodies to antigens in liver, spleen, red marrow, and lymph nodes has been reported (25). Therefore, the exchange across the capillary wall of other tissue is slow, compared with the fast transport and binding to antigen sites in such organs (28).

The distribution of labeled and unlabeled antibody was modeled in 2 separate circulation systems (Figs. 1 and 2). Competitive binding between the 2 circulation systems was implemented by the constraint of a stationary number of antigens, $\mathrm{Ag}_{\mathrm{i}}$, as shown in the supplemental equations and parameters (supplemental materials are available online only at http://jnm.snmjournals.org). In addition, it is assumed that labeled antibody moves into the unlabeled antibody compartment when the radiolabel decays (rate $\left.\lambda_{\text {phys }}\right)$.

Other important processes are the degradation of bound (rate $\lambda_{\mathrm{db}}$ ) and unbound (rate $\lambda_{\mathrm{du}}$ ) antibody and the clearance (rate $\lambda_{\mathrm{cl}}$ ) of degraded antibody. We assume that bound antibody is degraded at the same rate from all organs (27). Nonbound antibody degradation and clearance of the fraction of ${ }^{111}$ In-diethylenetriaminepentaacetic acid and ${ }^{111}$ In-low-molecular-weight biodistribution are described according to the empiric submodel of Eger et al. (Fig. 1) (27). Reported values of degradation in liver and other organs lie within a wide range, indicating the relevance of the specific chemical properties of the antibody and the applied dose. For most antibodies, Fc-receptor-mediated elimination plays an important role (21). However, the used antibody YAML568 has a modified Fc-receptor (9). To investigate the implications of that modification, we compared the model with degradation according to Eger et al. (model A, Fig. 1) to the model without degradation of unbound antibody (model B, Fig. 1). The corrected Akaike information criterion was used for model selection (31). Using this 
FIGURE 1. Structure of model for unlabeled antibody. Antibody is administered into veins that are part of main vascular compartment. Then, antibody is distributed according to blood flow to organs where it is bound to antigen. Degradation takes place in each organ where antibody is bound. Model A also includes degradation of unbound antibodies; model B does not include it. Corresponding part where model A and $B$ differ is framed (continuous line). Biodistribution of degraded antibody is described by empiric submodel. Models of unlabeled and labeled (not depicted but equivalent) antibody are connected by same number of antigens in organs and physical decay. $A b=$ antibody; $\mathrm{Ag}=$ antigen; $\mathrm{AgAb}=$ antibody bound to antigen; Ex = extravascular compartment; $\mathrm{Gl}$ = gastrointestinal tract; lymph n. = lymph nodes; Metap = metabolites in blood; Meta ex1 $_{1}$ and Meta $_{\mathrm{ex} 2}=$ extravascular metabolites; red mar. = red marrow; $v=$ vascular compartment.

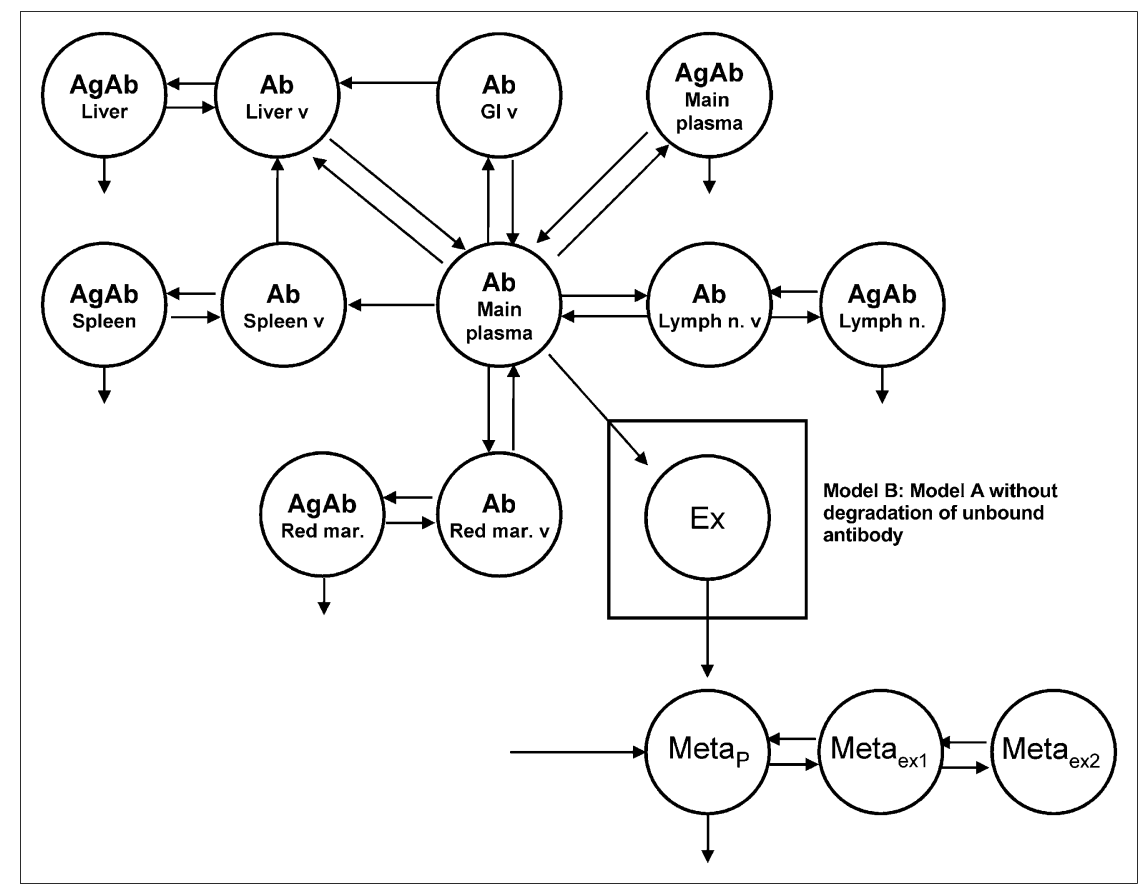

model selection approach, we calculated the probability (Akaike weights) that model A or B would be the best model.

The measured radiochemical purity was modeled by 2 injections into the respective compartments: the free antibody compartment and the Meta ${ }_{P}$ compartment (Fig. 1).

\section{Data Fitting and Parameter Estimation}

The estimated parameters of the models are the numbers of antigens in all organs, $\mathrm{Ag}_{\mathrm{i}}$; the total blood serum volume, $\mathrm{V}_{\text {total }}$; the degradation constant, $\lambda_{\mathrm{db}}$, of bound antibody; the association rate, $\mathrm{k}_{\mathrm{on}}$; and the effective dissociation constant, $\mathrm{K}_{\mathrm{D}} \cdot \mathrm{K}_{\mathrm{D}}$ is determined individually, since it varies greatly depending on the experimental conditions (32). One factor that in our case could strongly affect the value of $K_{D}$ is the ratio of applied antibody and the number of antigens, which is previously not known and has to be estimated. $\mathrm{k}_{\text {on }}$ is also estimated since the values are likely to be different from the values calculated in vitro (Table 2) (33). However, $\mathrm{k}_{\mathrm{on}}$ has to be determined globally, that is, fitted with the data of all patients, to keep the fitting process stable. This approximation will have a minor impact on the results, since $K_{D}$ is the relevant parameter, whereas $\mathrm{k}_{\text {on }}$ needs to be estimated but hardly affects the results (33). Studies have shown that blood flow is among the most powerful parameter of a PBPK model (19) and that acute leukemia can alter normal blood supply (34); therefore, blood flow was fitted with a Bayesian term deriving the SD from values published by Leggett and Williams (30) as a population mean. Radioactive decay was included in the differential equations (35) provided in the supplemental data.

The model was fitted to the data using SAAM2 (24). A relative data-weighting scheme with a fractional SD of 0.1 was assigned to all $(n=160)$ data. The Rosenbrock least squares algorithm was used, and the convergence criterion was set to $10^{-5}(24)$.

\section{Simulations}

To find the optimal preloading for the individual patients, we conducted simulations with 14 different preloading amounts of unlabeled antibodies (0-534 $\mathrm{nmol}$, corresponding to 0-80 $\mathrm{mg}$ ) using the model with its individually estimated parameters. The area under the curve, which is the relative number of decays (and therefore proportional to the residence time), was computed using SAAM2. The ratios of the residence times in liver and red marrow were used as a measure of favorable biodistribution. In addition, the ratios of residence times, $\tau_{\mathrm{rm}} / \tau_{\text {liver }}$, for the optimal and actual preloading amount of unlabeled antibody $(0.5 \mathrm{mg} / \mathrm{kg})$ were compared, with analysis of the potential for improving radioimmunotherapy by optimizing the preload.

The simulations and calculations were also performed for a $K_{D}$ 10-fold smaller because $K_{D}$ most presumably depends on the ratio of antibody and antigens, which is expected to decrease with a decreasing amount of preloaded antibody (32).

\section{RESULTS}

Model A, in which nonbound antibody was degraded according to the submodel of Eger et al., was found to be best, with a probability of $100 \%$ as determined by Akaike weights. Visual inspection of the graphs showed good fits (Fig. 3).

The values of the estimated parameters of model A are presented in Table 3. They indicate high interpatient variability. Especially the estimated number of antigens and the blood flows differ from patient to patient considerably. The calculated values $(0.35-4 \mathrm{nmol})$ of the number of antigens in the plasma using the counted leukocyte number and the antigen expression $\left(2 \times 10^{5}\right.$ per cell) were of the same magnitude as the estimated values (Table 3 ). The blood volume calculated according to a standard formula (given in the supplemental data) was in good agreement with the estimated volume (mean value of the ratio of estimated and calculated value was 1.01, and the range was 


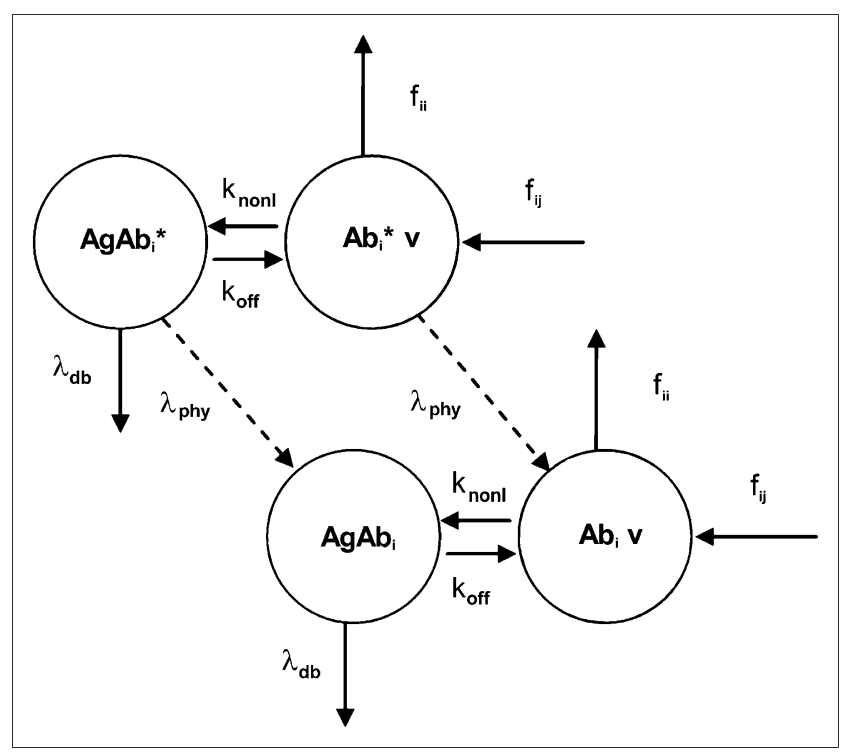

FIGURE 2. Competition of labeled and unlabeled antibody. $\mathrm{k}_{\text {nonl }}$ is nonlinear association rate and equals $\mathrm{k}_{\mathrm{on}}\left(\mathrm{Ag}_{\mathrm{i}}-\right.$ $\left.A g A b_{i}{ }^{*}-A g A b_{i}\right) / V_{i}, k_{\text {off }}$ is dissociation rate, $f_{i j}$ is transport of antibody via plasma flow to organ and equals $F_{i} / V_{j}$ (where $F_{i}$ is blood flow and $V_{j}$ is blood volume of preceding organ), $f_{i j}$ is transport of antibody via plasma flow out of organ and equals $F_{i} / V_{i}$ (where $F_{i}$ is blood flow and $V_{i}$ is blood volume of respective organ), ${ }^{*}$ is labeled; lack of * is unlabeled, $A g A b_{i}$ is bound antibody, $A b_{i}$ is free antibody, $v$ is vascular, $\lambda_{\text {phy }}$ is physical decay, and $\lambda_{\mathrm{db}}$ is degradation rate of antibodyantigen complex. First, plasma delivers administered unlabeled antibody to organs and binds according to flow and number of antigens in corresponding organ. Then, labeled antibody enters system and binds depending on still available antigen sites, as unlabeled and labeled antibodies are competing for free antigens. Connecting variables of unlabeled and labeled antibody system are total number of antigens in respective organ and physical decay of nuclide.

0.90-1.24). The fit yielded an affinity rate, $\mathrm{k}_{\mathrm{on}}$, of $1.62 \times$ $10^{7} \mathrm{~L} / \mathrm{mol} / \mathrm{min}$, which is in the typical range (33).

The results of all simulations of each patient are depicted in Figure 4. Lack of preloading leads to the worst biodistribution, and administering too much antibody obviously saturates the target organ. The maxima of the simulated ratios of residence times, $\tau_{\mathrm{rm}} / \tau_{\text {liver }}$, depend on the individual patients and are presented in Table 4. On the basis of the presented model, the optimal amount of unlabeled antibody would yield a residence time ratio, $\tau_{\text {rm }} / \tau_{\text {liver }}$, of 2.2-7.7, which would be a 1.6- to 2.4-fold improvement over the actually used preload (Table 4). At the same time, unlabeled antibody preload could be reduced to $24 \%-89 \%$ of the actually administered amount. Changing the dissociation constant, $\mathrm{K}_{\mathrm{D}}$, to a 10 -fold smaller value led to the same optimal preload and an even higher (3.2- to 7.1-fold) improvement.

\section{DISCUSSION}

To find the optimal dose of unlabeled antibody, which could further improve radioimmunotherapy using anti-
TABLE 2. Data Fixed or Weighted with Bayesian

Parameters for Each Organ

\begin{tabular}{|cccc} 
& & & \multicolumn{1}{c}{$\lambda_{\text {phy }}$} \\
\multicolumn{1}{c}{ Site } & $\mathrm{F}_{\mathrm{i}}^{*}(\%)$ & $\mathrm{V}_{\mathrm{i}}^{*}(\%)$ & ${ }^{111} \mathrm{In}(1 / \mathrm{min})$ \\
\hline Liver $^{\dagger}$ & 6.5 (arterial), & 10 & \\
& $25.5 \pm 2^{\ddagger}$ (total) & & \\
\hline Spleen & $3 \pm 2^{\S}$ & 1.4 & \\
\hline Red marrow & $3 \pm 3^{\S}$ & 4 & $1.72 \times 10^{4}$ \\
\hline Lymph nodes & 1.7 & 0.2 & \\
Gastrointestinal tract & 16 & 7.6 & \\
\hline Plasmall & - & 66.8 & \\
\hline
\end{tabular}

${ }^{*}$ Data are from Leggett et al. (30).

${ }^{+}$Liver is supported by direct arterial flow (6.5\% of total blood flow), plus portal flow from gastrointestinal tract (16\%) plus flow from spleen (3\%).

${ }^{\ddagger} \mathrm{SD} \pm 2$ stems from Bayesian term of spleen.

"Plasma includes blood pools other than liver, spleen, red marrow, and lymph nodes. Exchange between veins, arteries, heart, and other blood pools is fast, and therefore blood pools of organs with no antigen site can be simplified to one.

${ }^{\S}$ Blood flows were determined using Bayesian term. For flow to lymph nodes, mean population value was used since no direct measurement of lymph node time-activity curve would otherwise yield high uncertainties for both its flow and number of antigens. Arterial flow to liver was fixed because starting value of $6.5 \%$ was also fitted value in all cases.

CD45 antibody, we developed a PBPK model that describes measured time-activity data. PBPK models are advantageous since parameters have a physiologic meaning and thus are measurable (18). Models that are physiologically based also allow the simulation of other conditions, such as the varying amounts of unlabeled antibody. In our model, which includes blood flow to the organs and competitive binding of labeled and unlabeled antibody, some parameter values were taken from the literature and others were estimated from the individual patient data. An individualized approach for each patient was developed since it has been suggested that the optimal preloading dose is patientdependent (9).

In vitro measurements of $K_{D}$ do not represent in vivo values (33). For example, a lower concentration might lead to a double binding that is up to $10^{5}$-fold stronger or higher than the values determined in vitro (36). Therefore, the $K_{D}$ values in our model have to be considered effective values, which were estimated to be 63- to 146-fold lower than the in vitro values. Patient 2 had a 10 -fold lower $\mathrm{K}_{\mathrm{D}}$ (Table 3), reflecting the higher Ak/Ag ratio of 2.5. All results for $K_{D}$ agree well with the measurements of other studies (33). The estimated values for $K_{D}$ vary with the ratio of administered antibody and antigens. This result confirms the finding of Ong and Mattes (32) that $\mathrm{K}_{\mathrm{D}}$ strongly depends on the experimental conditions.

The total plasma volume had to be fitted in our model, since standard methods to estimate the total plasma value 

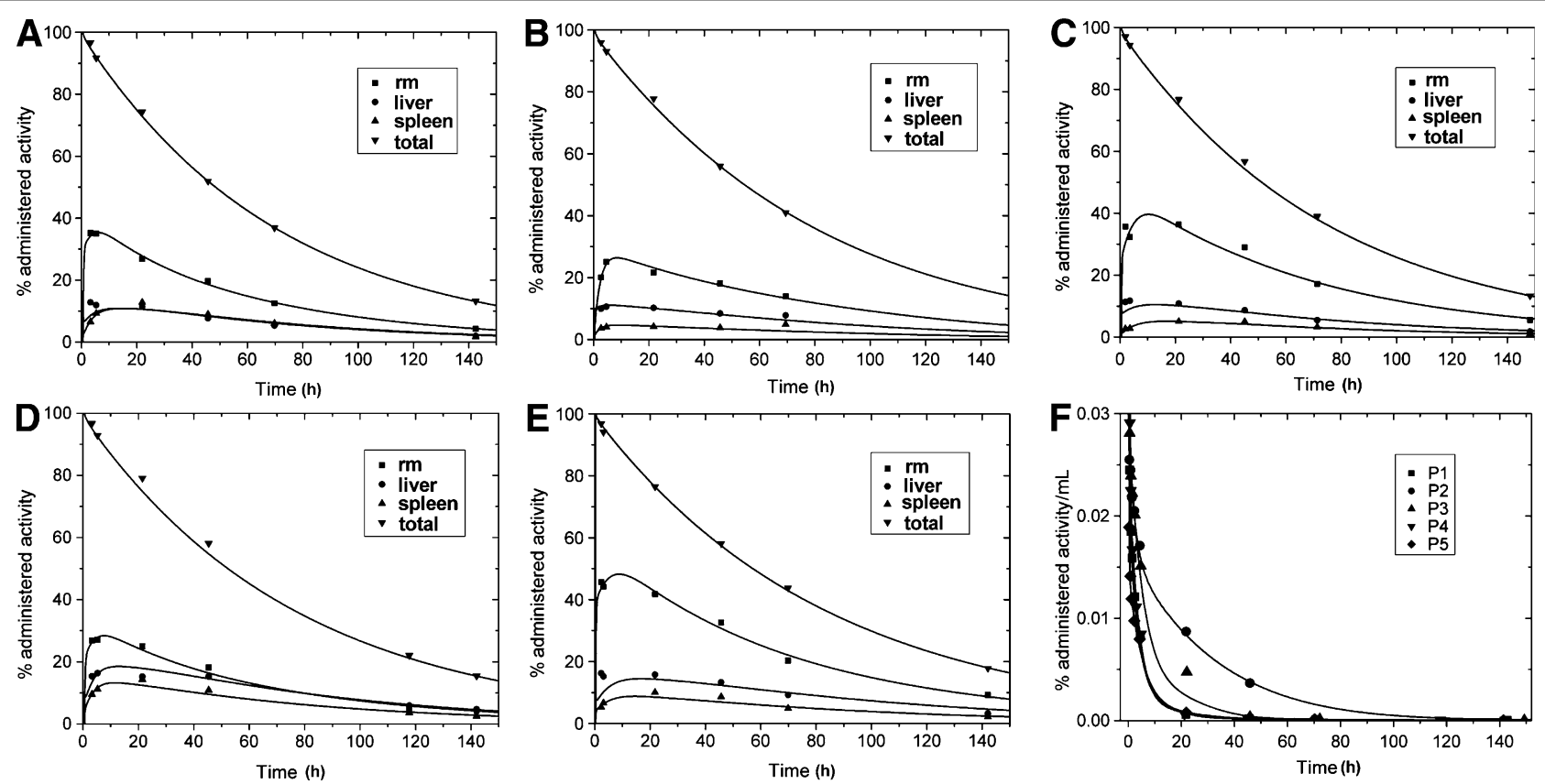

FIGURE 3. Time-activity data and fitted curves for all patients. rm = red marrow.

(given in the supplemental data) do not include all patientspecific deviations, especially those caused by diseases. However, the fitted parameters agreed well with values calculated using such standard methods, demonstrating the reliability of the model. A further indication that the fitted parameters actually represent physiologic quantities is that for patients 2 and 4 hypocellularity of the red marrow was confirmed by a lower estimated number of antigens. The predosimetric calculation of antigens (other than in the blood) is not reasonable since the number of "readily accessible" (25) antigens depends on the number of leukocytes and their precursors, the actual expression of antigens per cell, and the accessibility of the cells. This makes an individualized approach indispensable. Noteworthy, the degradation rate of bound antibody is on the same order of magnitude as the value determined by Eger et al. (27).
The residence times for different preloading conditions for each organ and all patients were calculated on the basis of the individually estimated PBPK model parameters. The ratio of residence times, $\tau_{\mathrm{rm}} / \tau_{\text {liver }}$, could be improved by a factor of up to 2.4 (Table 4). Especially for patients in whom high blood activity was observed at $10 \mathrm{~h}$ after injection (patients 2 and 3), a considerably improved biodistribution was obtained by the simulations with lower doses of unlabeled antibody.

For radioimmunotherapy, targeting CD33 (37) and CD66 (4) antigens leads to ratios of approximately 3 and 5, respectively, for residence time in red marrow to residence time in liver. Optimizing the amount of unlabeled antibody, we could reach ratios of 2.2-7.7 for residence time in red marrow to residence time in liver $\left(\tau_{\text {liver }} / \tau_{\mathrm{rm}}\right)$ using antiCD45 in this study - ratios that compare favorably with the ratios of anti-CD33 and anti-CD66 antibodies.

\begin{tabular}{|c|c|c|c|c|c|c|c|c|c|c|}
\hline \multirow[b]{2}{*}{$\begin{array}{c}\text { Patient } \\
\text { no. }\end{array}$} & \multirow[b]{2}{*}{$\begin{array}{l}F_{r m} \\
(\%)\end{array}$} & \multirow[b]{2}{*}{$\begin{array}{c}F_{\text {spleen }} \\
(\%)\end{array}$} & \multicolumn{5}{|c|}{ Amount of antigen (nmol) } & \multirow[b]{2}{*}{$\begin{array}{c}\mathrm{K}_{\mathrm{D}} \\
(\mathrm{nmol} / \mathrm{L})\end{array}$} & \multirow[b]{2}{*}{$\begin{array}{c}\lambda_{\mathrm{db}} \\
\left(10^{-5} / \mathrm{min}\right)\end{array}$} & \multirow[b]{2}{*}{$\begin{array}{c}V_{\text {total }} \\
(\mathrm{L})\end{array}$} \\
\hline & & & Plasma & $\begin{array}{l}\text { Red } \\
\text { marrow }\end{array}$ & Liver & Spleen & $\begin{array}{l}\text { Lymph } \\
\text { node }\end{array}$ & & & \\
\hline 1 & $1.6 \pm 0.4$ & $1.5 \pm 0.5$ & $1.2 \pm 0.4$ & $91.1 \pm 8.0$ & $53.4 \pm 6.1$ & $56.8 \pm 5.5$ & $80.1 \pm 7.4$ & $0.03 \pm 0.01$ & $6.7 \pm 0.17$ & $3.10 \pm 0.35$ \\
\hline 2 & $4.1 \pm 3.6$ & $3.0 \pm 2.4$ & $0.3 \pm 0.2$ & $83.2 \pm 2.3$ & $16.0 \pm 2.4$ & $12.3 \pm 1.9$ & $0.0 \pm 0.0$ & $0.31 \pm 0.11$ & $6.6 \pm 0.78$ & $3.62 \pm 0.76$ \\
\hline 3 & $2.4 \pm 0.4$ & $3.0 \pm 2.4$ & $0.9 \pm 0.4$ & $122.5 \pm 8.3$ & $36.7 \pm 4.3$ & $21.1 \pm 2.1$ & $54.8 \pm 10.8$ & $0.04 \pm 0.01$ & $5.7 \pm 0.35$ & $2.76 \pm 0.30$ \\
\hline 4 & $2.3 \pm 0.6$ & $2.2 \pm 0.7$ & $1.0 \pm 0.2$ & $52.2 \pm 4.3$ & $60.2 \pm 4.0$ & $37.9 \pm 2.6$ & $36.8 \pm 4.6$ & $0.02 \pm 0.01$ & $4.7 \pm 0.38$ & $3.19 \pm 0.25$ \\
\hline 5 & $7.8 \pm 1.7$ & $3.7 \pm 1.3$ & $1.2 \pm 0.4$ & $136.5 \pm 9.3$ & $79.6 \pm 12.3$ & $41.2 \pm 4.1$ & $20.0 \pm 10.2$ & $0.02 \pm 0.01$ & $2.8 \pm 0.17$ & $3.95 \pm 0.40$ \\
\hline Mean & $3.6 \pm 2.5$ & $2.7 \pm 0.9$ & $0.9 \pm 0.4$ & $97 \pm 33$ & $49 \pm 24$ & $34 \pm 18$ & $38 \pm 31$ & $0.10 \pm 0.14$ & $5.3 \pm 1.6$ & $3.32 \pm 0.46$ \\
\hline
\end{tabular}




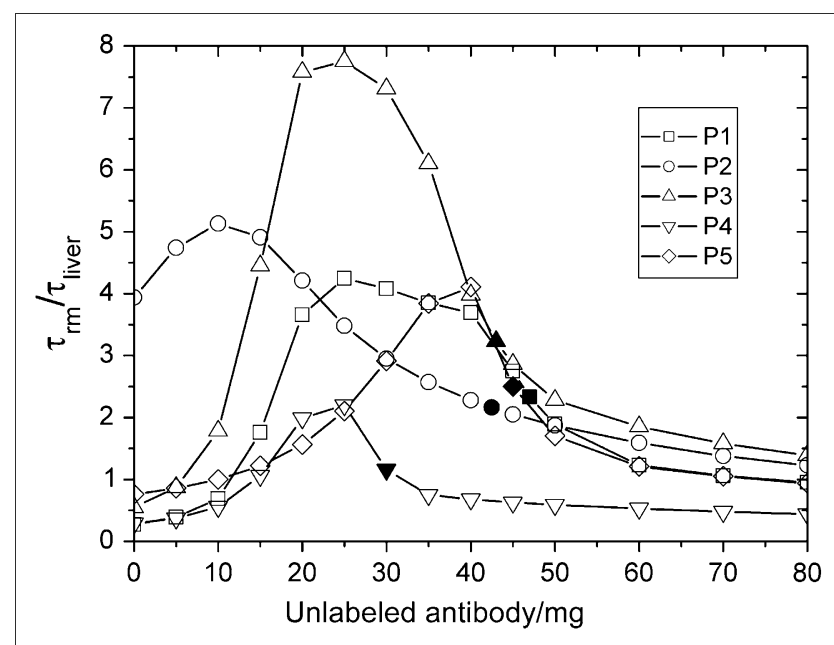

FIGURE 4. Ratios of residence time of red marrow and liver with varying preload of unlabeled antibody. $\mathrm{rm}=$ red marrow.

Notably, the measured residence times obtained for our patients with $10 \mathrm{mg}$ or no unlabeled antibody (data of these patients were not adequate to be fitted) (9) yield values of the same magnitude as predicted for the patients investigated here. This can be considered a first confirmation of the predictive power of the model. Nevertheless, our findings need further validation using additional measurements: the model has been established and validated in a small population ( 5 cases), and for the investigated patients the optimal amount of unlabeled antibody was found to be considerably lower than the actual administered amount (Table 4). Especially, the extrapolation from the injected amount of antibody to the optimal amount needs further experimental proof. A straightforward investigation of the predictive power of this model can be investigated by obtaining 2 consecutive measurements with 2 different preloading conditions in the same patient. Further simulation work has to be done to find the best combination of measurements for this validation of the model.

\begin{tabular}{|c|c|c|c|c|c|}
\hline $\begin{array}{c}\text { Patient } \\
\text { no. }\end{array}$ & $\begin{array}{l}\text { Administered } \\
\text { amount } \\
\text { (mg) }\end{array}$ & $\begin{array}{l}\text { Optimal } \\
\text { amount }^{\dagger} \\
\text { (mg) }\end{array}$ & $\begin{array}{l}\text { Actual } \\
\text { ratio } \\
\left(\tau_{\text {rm }} / \tau_{\text {liver }}\right)\end{array}$ & $\begin{array}{l}\text { Optimal } \\
\text { ratio } \\
\left(\tau_{\mathrm{rm}} / \tau_{\text {liver }}\right)\end{array}$ & $\begin{array}{l}\text { Factor } \\
\text { of } \\
\text { improvement }\end{array}$ \\
\hline 1 & 47 & 25 & 2.4 & 4.3 & 1.8 \\
\hline 2 & 42.5 & 10 & 2.1 & 5.1 & 2.4 \\
\hline 3 & 43 & 25 & 3.3 & 7.7 & 2.4 \\
\hline 4 & 30 & 25 & 1.2 & 2.2 & 1.9 \\
\hline 5 & 45 & 40 & 2.5 & 4.1 & 1.6 \\
\hline \multicolumn{6}{|c|}{$\begin{array}{l}{ }^{*} \text { Absorbed dose is directly proportional to residence time. } \\
{ }^{\dagger} \text { As determined by simulating different preloads (amounts of } \\
\text { unlabeled antibody). }\end{array}$} \\
\hline
\end{tabular}

The validated model will be integrated into clinical routine as follows: first, standard dosimetry data are used to estimate the patient-specific model parameters, which are the basis for subsequent simulations of the therapy. Second, simulations with various amounts of unlabeled antibody (preloads) are conducted to identify the most favorable biodistribution for therapy. Third, the calculated optimal therapy is performed (including additional quality control measurements).

The presented PBPK model is flexible and extendible for radioimmunotherapy of other hematologic malignancies for which blood flow and competitive binding of antibody are relevant, such as those in which CD20, CD33, or CD66 is targeted. The fact that CD33 is also expressed on tissue macrophages in the liver (10) indicates that radioimmunotherapy with anti-CD33 might be improved with a preload optimized by the presented approach. Furthermore, our presented model is also applicable for describing the biodistribution of antibody-chemotherapy conjugates in which the application of a preload of unlabeled antibody would reduce chemical toxicity, especially of the liver (38).

\section{CONCLUSION}

The presented PBPK model adequately describes the biodistribution of anti-CD45 antibody. The need for an individualized approach has been confirmed, since the fits yielded considerable differences in the number of antigens and the blood flow to the red marrow and spleen for the investigated patients. The model allows simulating different preloading conditions to determine the optimal unlabeled amount for each individual. A 1.6- to 2.4-fold improvement of the ratio of residence time in red marrow to residence time in liver shows the great potential of this approach. The presented method is a major step toward the goal of individually determining pharmacokinetics-based optimal preloading for ${ }^{90} \mathrm{Y}$-labeled anti-CD45 antibody therapy of hematologic malignancies. The method potentially can be extended to radioimmunotherapy with other antibodies for which unwanted binding of labeled antibody in the liver or spleen occurs. The validation of the prediction power of the model is ongoing.

\section{ACKNOWLEDGMENTS}

We gratefully acknowledge a grant (GL 236/7-1) from the Deutsche Forschungsgemeinschaft (DFG, German Research Foundation).

\section{REFERENCES}

1. Dearling JL, Pedley RB. Technological advances in radioimmunotherapy. Clin Oncol (R Coll Radiol). 2007;19:457-469.

2. Jurcic JG, Caron PC, Nikula TK, et al. Radiolabeled anti-CD33 monoclonal antibody M195 for myeloid leukemias. Cancer Res. 1995;55:5908s-5910s.

3. Jurcic JG. Immunotherapy for acute myeloid leukemia. Curr Oncol Rep. 2005;7:339-349.

4. Bunjes D, Buchmann I, Duncker C, et al. Rhenium 188-labeled anti-CD66 (a, b, $\mathrm{c}, \mathrm{e})$ monoclonal antibody to intensify the conditioning regimen prior to stem 
cell transplantation for patients with high-risk acute myeloid leukemia or myelodysplastic syndrome: results of a phase I-II study. Blood. 2001;98:565572.

5. Ringhoffer M, Blumstein N, Neumaier B, et al. ${ }^{188}$ Re- or ${ }^{90}$ Y-labelled anti-CD66 antibody as part of a dose-reduced conditioning regimen for patients with acute leukaemia or myelodysplastic syndrome over the age of 55: results of a phase I-II study. Br J Haematol. 2005;130:604-613.

6. Reske SN, Bunjes D, Buchmann I, et al. Targeted bone marrow irradiation in the conditioning of high-risk leukaemia prior to stem cell transplantation. Eur J Nucl Med. 2001;28:807-815.

7. Matthews DC, Appelbaum FR, Eary JF, et al. Phase I study of ${ }^{131} \mathrm{I}$-anti-CD45 antibody plus cyclophosphamide and total body irradiation for advanced acute leukemia and myelodysplastic syndrome. Blood. 1999;94:1237-1247.

8. Pagel JM, Appelbaum FR, Eary JF, et al. ${ }^{131} \mathrm{I}$-anti-CD45 antibody plus busulfan and cyclophosphamide before allogeneic hematopoietic cell transplantation for treatment of acute myeloid leukemia in first remission. Blood. 2006;107:21842191.

9. Glatting G, Müller M, Koop B, et al. Anti-CD45 monoclonal antibody YAML568: a promising radioimmunoconjugate for targeted therapy of acute leukemia. J Nucl Med. 2006;47:1335-1341.

10. Abutalib SA, Tallman MS. Monoclonal antibodies for the treatment of acute myeloid leukemia. Curr Pharm Biotechnol. 2006;7:343-369.

11. Goldenberg DM, Sharkey RM, Paganelli G, Barbet J, Chatal JF. Antibody pretargeting advances cancer radioimmunodetection and radioimmunotherapy. $J$ Clin Oncol. 2006;24:823-834.

12. Sharkey RM, Goldenberg DM. Perspectives on cancer therapy with radiolabeled monoclonal antibodies. J Nucl Med. 2005;46:115S-127S

13. Nemecek ER, Hamlin DK, Fisher D, et al. Biodistribution of yttrium-90-labeled anti-CD45 antibody in a non human primate model. Clin Cancer Res. 2005;11: 787-794.

14. Knox SJ, Goris M, Trisler K, et al. Yttrium-90-labeled anti-CD20 monoclonal antibody therapy of recurrent B-cell lymphoma. Clin Cancer Res. 1996;2:457470.

15. Matthews DC. Development of a marrow transplant regimen for acute leukemia using targeted hematopoietic irradiation delivered by ${ }^{131}$ I-labeled anti-CD45 antibody, combined with cyclophosphamide and total body irradiation. Blood. 1995;85:1122-1131.

16. Sandmaier BM, Bethge WA, Wilbur DS, et al. Bismuth 213-labeled anti-CD45 radioimmunoconjugate to condition dogs for nonmyeloablative allogeneic marrow grafts. Blood. 2002;100:318-326.

17. Charnick SB, Kawai R, Nedelman JR, Lemaire M, Niederberger W, Sato H. Perspectives in pharmacokinetics. Physiologically based pharmacokinetic modeling as a tool for drug development. J Pharmacokinet Biopharm. 1995;23:217229.

18. Baxter LT, Zhu H, Mackensen DG, Butler WF, Jain RK. Biodistribution of monoclonal antibodies: scale-up mouse to human using a physiologically based pharmacokinetic model. Cancer Res. 1995;55:4611-4622.

19. Nestorov I. Whole body pharmacokinetic models. Clin Pharmacokinet. 2003;42: 883-908.
20. Ferl GZ, Wu AM, DiStefano JJ III. A predictive model of therapeutic monoclonal antibody dynamics and regulation by the neonatal $\mathrm{Fc}$ receptor $(\mathrm{FcRn})$. Ann Biomed Eng. 2005;33:1640-1652.

21. Ferl GZ, Kenanova V, Wu AM, DiStefano JJ III. A two-tiered physiologically based model for dually labeled single-chain Fv-Fc antibody fragments. Mol Cancer Ther. 2006;5:1550-1558.

22. Green AJ, Johnson CJ, Adamson KL, Begent RH. Mathematical model of antibody targeting: important parameters defined using clinical data. Phys Med Biol. 2001;46:1679-1693.

23. Glatting G, Landmann M, Kull T, et al. Internal radionuclide therapy: the UlmDos software for treatment planning. Med Phys. 2005;32:2399-2405.

24. Barrett PH, Bell BM, Cobelli C, et al. SAAM II: simulation, analysis, and modeling software for tracer and pharmacokinetic studies. Metabolism. 1998;47: 484-492.

25. Matthews DC, Appelbaum FR, Eary JF, et al. Radiolabeled anti-CD45 monoclonal antibodies target lymphohematopoietic tissue in the macaque. Blood. 1991;78: 1864-1874.

26. Matthews DC, Badger CC, Fisher DR, et al. Selective radiation of hematolymphoid tissue delivered by anti-CD45 antibody. Cancer Res. 1992;52:1228-1234.

27. Eger RR, Covell DG, Carrasquillo JA, et al. Kinetic model for the biodistribution of an ${ }^{111}$ In-labeled monoclonal antibody in humans. Cancer Res. 1987;47:3328-3336.

28. Rippe B, Haraldsson B. Transport of macromolecules across microvascular walls: the two-pore theory. Physiol Rev. 1994;74:163-219.

29. Montesano R, Nicolescu P. Fenestrations in endothelium of rat liver sinusoids revisited by freeze-fracture. Anat Rec. 1978;190:861-887.

30. Leggett RW, Williams LR. A proposed blood circulation model for reference man. Health Phys. 1995;69:187-201.

31. Glatting G, Kletting P, Reske SN, Hohl K, Ring C. Choosing the optimal fit function: comparison of the Akaike information criterion and the F-test. Med Phys. 2007;34:4285-4292.

32. Ong GL, Mattes MJ. Re-evaluation of the concept of functional affinity as applied to bivalent antibody binding to cell surface antigens. Mol Immunol. 1993;30: 1455-1462.

33. Thomas GD, Chappell MJ, Dykes PW, et al. Effect of dose, molecular size, affinity, and protein binding on tumor uptake of antibody or ligand: a biomathematical model. Cancer Res. 1989;49:3290-3296.

34. Iversen PO, Thing-Mortensen B, Nicolaysen G, Benestad HB. Decreased blood flow to rat bone marrow, bone, spleen, and liver in acute leukemia. Leuk Res. 1993;17:663-668.

35. Glatting G, Reske SN. Treatment of radioactive decay in pharmacokinetic modeling: influence on parameter estimation in cardiac ${ }^{13} \mathrm{~N}-\mathrm{PET}$. Med Phys. 1999;26:616-621.

36. Gopalakrishnan PV, Karush F. Antibody affinity. VII. Multivalent interaction of anti-lactoside antibody. J Immunol. 1974;113:769-778.

37. Jurcic J-G, Larson S-M, Sgouros G, et al. Targeted alpha particle immunotherapy for myeloid leukemia. Blood. 2002;100:1233-1239.

38. Rajvanshi P, Shulman HM, Sievers EL, McDonald GB. Hepatic sinusoidal obstruction after gemtuzumab ozogamicin (Mylotarg) therapy. Blood. 2002;99: 2310-2314. 